\title{
DRAMAFEVER: UMA ANÁLISE DAS INTERAÇÕES ENTRE MARCA E CONSUMIDOR
}

\author{
DRAMAFEVER: AN ANALYSIS \\ ON BRAND AND CONSUMER INTERACTIONS
}

DRAMAFEVER: UN ANALISIS DE LA MARCA
YLAS INTERACCIONES DEL CONSUMIDOR.

Raíssa ABRACADO; Danuta LEÃO.

RESUMO

Este artigo tem como objetivo analisar as estratégias de marketing digital, abordando a interação entre marca e consumidor como parte da estratégia, na fanpage DramaFever Brasil. O objeto de pesquisa é a plataforma de streaming Dramafever. A empresa foi um site de compartilhamentos de dramas e conteúdos asiáticos do mundo. Para melhor compreensão, estudou-se o cenário e hábitos dos individuos na cibercultura, abordando conceitos de consumo, relação com as marcas e os papéis que os individuos hoje possuem na indústria midiática. O estudo é importante para compreender como a relacão entre marca e consumidor está sendo construida no ambiente digital, analisando as posturas assumida quanto ao engajamento de seus produtos, ressaltado a importância do diálogo e sincronia para atrair, conquistar e fidelizar o seu público.

PALAVRAS-CHAVE:

Marketing Digital; Dramafever; Interação; Facebook.
ABSTRACT

This article intends to analyze digital marketing strategies, addressing the interaction between brand and consumer as part of the strategy, on the DramaFever Brasil fanpage. The research subject is the streaming platform Dramafever. the company was the main site sharing Asian content in the world. For a better understanding, the research studies the scenario and habits of individuals in cyberculture, connecting concepts of consumption, relationship with brands and the roles that individuals have in the media industry. The study is important to understand how the relationship between brand and consumer is being built in the digital environment, analyzing the positions taken regarding the spread of their products, highlighting the importance of dialogue and sync to attract, conquer and retain their audience.

\section{KEYWORDS:}

Digital Marketing; DramaFever: Interaction; Facebook.
RESUMEN

Este artículo pretende analizar las estrategias de "marketing" digital, abordando la interacción entre la marca y el consumidor como parte de la estrategia, en la página de fans de DramaFever Brasil. El objeto de investigación es la plataforma de transmisión Dramafever, la compañía era el sitio principal que compartía contenido asiático en el mundo. Para una mejor comprensión se estudió el escenario y los hábitos de las personas en la cibercultura, abordando conceptos de consumo, relación con las marcas y los roles que las personas tienen en la industria mediática. El estudio es importante para comprender cómo se está construyendo la relación entre la marca y el consumidor en el entorno digital, analizando las posiciones tomadas con respecto a la difusión de sus productos, destacando la importancia del diálogo y la sincronización para atraer, conquistar y retener su audiencia.

PALABRAS CLAVE:

Marketing Digital; Dramafever; Interacción; Facebook. 


\section{A ONDA COREANA}

A Coreia do Sul possui cinco mil anos de uma história em que se desenvolveu sua própria cultura. Foi um país que sofreu com longos períodos de guerra e colonialismo seguido de uma guerra civil nos anos 1950. O país estava com suas bases econômicas e sociais destruídas, precisava se reestruturar praticamente do zero, começando esforços para alcançar as nações mais desenvolvidas. Nesse contexto, a cultura não seria uma exceção no desenvolvimento coreano.

Ao longo dos 5000 anos da história da Coreia do Sul, o país se apresentou receptivo a costumes e produtos estrangeiros, absorvendo o Budismo, Confucionismo e tradições chinesas (KOREAN CULTURE AND INFORMATION SERVICE, 2011a). Mais recentemente trouxe para si o estilo de vida e a educação americana, a filosofia europeia e a modernidade japonesa. Durante as guerras - uma no próprio país e outra no Vietnã importou estilos de músicas americanas, como o folk e o rock, assim como outros estilos de música francesa, italiana e até mesmo latinas. Logo, músicos locais começaram a reproduzir esses estilos, o que gerou uma grande popularidade de músicas estrangeiras no país. Nos anos 1980, após décadas de industrialização, quando o país já conseguia prover lazer e entretenimento, mais produções das culturas americanas e europeias passaram a ser transmitidas e, com a democratização da nação, as regulamentações de importação de cultura de outros países foi enfraquecida, o que resultou na tendência de ouvir músicas americanas e europeias no rádio
(KOREAN CULTURE AND INFORMATION SERVICE, 2011a), assim como séries americanas na tevê e filmes de Hollywood e Hong Kong nos cinemas. Entretanto, na metade dos anos 1990, a música pop coreana ganhou evidência trazendo diversos estilos e música de alta qualidade (KOREAN CULTURE AND INFORMATION SERVICE, 2011a. Álbuns estrangeiros, que antes dominavam o mercado por 10 anos, estavam sendo banidos e perdendo seu prestígio no mercado.

Com menos de uma década, a indústria sul coreana lançou grandes artistas locais, reconquistando o espaço no mercado com o pop coreano. E, nos incontáveis canais de TV a cabo, os dramas coreanos passavam $24 \mathrm{~h}$ por dia; nos finais de semana, os cinemas estavam lotados para ver filmes coreanos. A Coreia se tornou uma das poucas nações que consomem mais produções culturais locais do que estrangeiras e isso começou a se expandir para além das fronteiras coreanas, iniciando a Hallyu (KOREAN CULTURE AND INFORMATION SERVICE, 2011a).

Hallyu significa "onda coreana", o termo foi designado por um jornalista chinês, em meados da década de 1990, para descrever - rápido crescimento e popularização do entretenimento coreano e a a cultura do país (KOREAN CULTURE AND INFORMATION SERVICE, 2011b). Na década de 1990, quando a Coreia do

Sul firmou relações diplomáticas com a China (em 1992), este último país passou a transmitir as novelas coreanas em sua programação televisiva. No final dessa década, o drama What is love? conquistou a audiência chinesa. Com um enredo que trouxe valores religiosos e ênfase nas tradições familiares, o drama atingiu o segundo lugar no ranking de audiência televisiva.

Depois do sucesso dos dramas coreanos, os cantores também começaram a entrar no mercado da China, Hong Kong e Taiwan. A dupla masculina Clon e os grupos de idols H.O.T, NRG, Baby V.O.X e S.E.S eram bastante presentes nas paradas de sucesso, nesses países e no sudoeste da Ásia, reunindo milhares de fãs nos shows. A Hallyu conseguiu, em menos de um ano, superar os sentimentos de desconfiança e desinteresse que persistia entre coreia e China por meio século desde a Guerra Coreana, fazendo mais do que os diplomatas fizeram em décadas.

A onda coreana chegou ao Japão no ano de 2003, quando a série da produtora KBS, Winter Sonata (2002), foi transmitida pelo canal de televisão japonês, NHK. Com a fórmula do sucesso para televisão, o drama trouxe belos atores, um cenário sofisticado e um enredo bastante piegas, com temas de amor, morte e saudades irreparáveis, amparadas por uma trilha sonora melancólica. O drama teve forte influência na sociedade japonesa, fez com que o turismo de japoneses à Coréia aumentasse e gerou o interesse em aprender a língua coreana.

O grande sucesso internacional de What Is Love? (MBC) e de Winter Sonata (KBS), na China e no Japão, foram fundamentais para impulsionar a paixão pelas telenovelas coreanas em toda a Ásia e no restante do mundo. Outros sucessos vieram logo após como, Jewel in the Palace 
(MBC, 2003), uma série de TV com tema histórico, inicialmente exibida entre 2003 e 2004. Essa novela foi um dos programas de TV com maior audiência na Coreia antes de ser exportada para 87 países, incluindo os países islâmicos como o Irã, onde ela conquistou cerca de 80\% da audiência, fascinando os telespectadores com o retrato da tradicional cultura coreana, como a cozinha da Corte Real, os trajes tradicionais e o conhecimento medicinal.

O sucesso das novelas continuou na década de 2010 com Big Thing (SBS, 2010), Giant (SBS, 2010), Secret Garden (SBS, 2011) e Love Rain (KBS, 2012). Em 2013, a novela That Winter, the Wind Blows foi exportada para algumas emissoras locais da América do Norte, bem como para dez países asiáticos, incluindo a China e o Japão. As novelas coreanas chegaram à América Latina por meio dos fansubs que, por muito tempo, foram o único meio de acesso no Brasil, até 2014, quando houve o lançamento do serviço de streaming especializado no gênero. Atualmente, existem outras plataformas que também oferecem o conteúdo como Netflix, Viki e recentemente o Kocowa, que lançou seu serviço no Brasil.

\section{K-DRAMA}

Diferente do contexto ocidental, o termo "drama" não se refere ao gênero, mas sim ao formato televisivo que engloba ficções seriadas produzidas, principalmente, no Sudeste Asiático. O formato surgiu no Japão na década de 1950 que, com o passar do tempo, ganhou características regionais, surgindo os 3 TW-Drama, K-

Drama, C-Dramas, entre outros, com temáticas do dia-a-dia que tratam de relacionamentos amorosos, familiares, contextos históricos e rotinas escolares.

Os Doramas ${ }^{4}$ surgiram com o intuito de reconstruir a ideia de cultura nacional sólida, que fora enfraquecida pela Segunda Guerra Mundial. As primeiras histórias retratavam os costumes e tradições da sociedade japonesa, ficando conhecidos como home dorama. Com o tempo surgiu os trendy dramas, os roller coast dramas e os cartoon dramas, que são narrativas adaptadas dos mangás. Esse gênero ajudou a popularizar os dramas de TV para os públicos estrangeiros consumidores de mangás e animes, como é o caso do Brasil.

Dentre os países asiáticos que tiveram sucesso na produção do formato, a Coreia do Sul ganha destaque devido à enorme produção anual, à atenção que conquistaram dentro e fora do país (MARTEL, 2012, apud, MADUREIRA; MONTEIRO; CORTEZ, 2014) e, em consequência, é a que mais exporta títulos para outros países. O Japão, mesmo sendo o originário do formato, não exporta tanto quanto a Coreia do sul.

O grande sucesso dos dramas coreanos se dá pelo enredo híbrido: ao mesmo tempo em que trata da Coreia do Sul, consegue unir influencias asiáticas e ocidentais, tornando possível combinar narrativas com modernidade e tradição, articulando com o Confucionismo, que é parte estrutural da cultura coreana, o qual trata o lado tradicional e moral da sociedade, em que prega $\mathrm{O}$ respeito aos mais velhos, à hierarquia e a

\section{importância da família (MADUREIRA; CORTEZ, 2014) MONTEIRO;}

Geralmente, a estrutura dos dramas coreanos é feita por temporadas únicas entre 8 e 25 episódios, podendo se estender para números maiores, em caso de temáticas e categorias específicas, onde cada episódio tem uma duração média de 1 hora. Essa formatação de temporadas únicas acontece porque abrem-se arcos grandes no primeiro episódio e se fecham no último, tendo pouco espaço para temporadas seguintes, sendo assim, as histórias mantêm $\mathrm{O}$ foco direcionado, com poucos núcleos de personagem.

\section{O DRAMAFEVER}

O Dramafever foi o primeiro e um dos maiores sites internacionais a oferecer serviços de streaming on demand, com filmes asiáticos e séries televisivas. Foi lançado no ano de 2009 pelos cofundadores Seung Bak e Suk Park, na cidade de Nova Yorque, começando apenas com séries de dramas coreanos. Em poucos anos, tornou-se líder desse seguimento, passando a oferecer séries e filmes de todo o mundo. Em 2016, o Dramafever se tornou uma filial da Warner Bros, no entanto, em outubro de 2018, o site encerrou as atividades inesperadamente sem muitas explicações, apenas alegando razões de negócios, uma vez que o mercado havia mudado (SPANGLER, 2018).

A plataforma oferecia centenas de séries, variados programas, filmes e entretenimento infantil, tudo traduzido em várias línguas. A audiência cresceu constante, obtendo fãs desde a América (Norte e Sul) à 
Austrália. O Brasil era o segundo maior mercado em termos de assinantes e vídeos assistidos, perdendo para os EUA e se mantendo à frente de países como Canadá e México. A plataforma possuía 21 milhões de visitas mensais por desktop e - Brasil representava 9\% desses acessos.

O site possuía a versão gratuita e premium: na gratuita eram restritos os dramas e filmes, sendo que em todo episódio gratuito existe a exibição de propagandas intervaladas ao longo do tempo; na premium o usuário tem acesso a todos os conteúdos disponíveis para o país em resolução HD, sem a exibição de propagandas durante os episódios.

No site (Figura O1) era possível fazer uma lista dos conteúdos que se desejaria assistir, navegar em busca de novos programas e interagir na plataforma por meio de comentários, abrindo uma vasta possibilidade de conteúdos como filmes, k-pop e notícias. A empresa também possuía outros canais de comunicação como, Facebook, Twitter, Instagram e YouTube, onde disponibilizava outros tipos de conteúdo.

Figura 1 - Site DramaFever

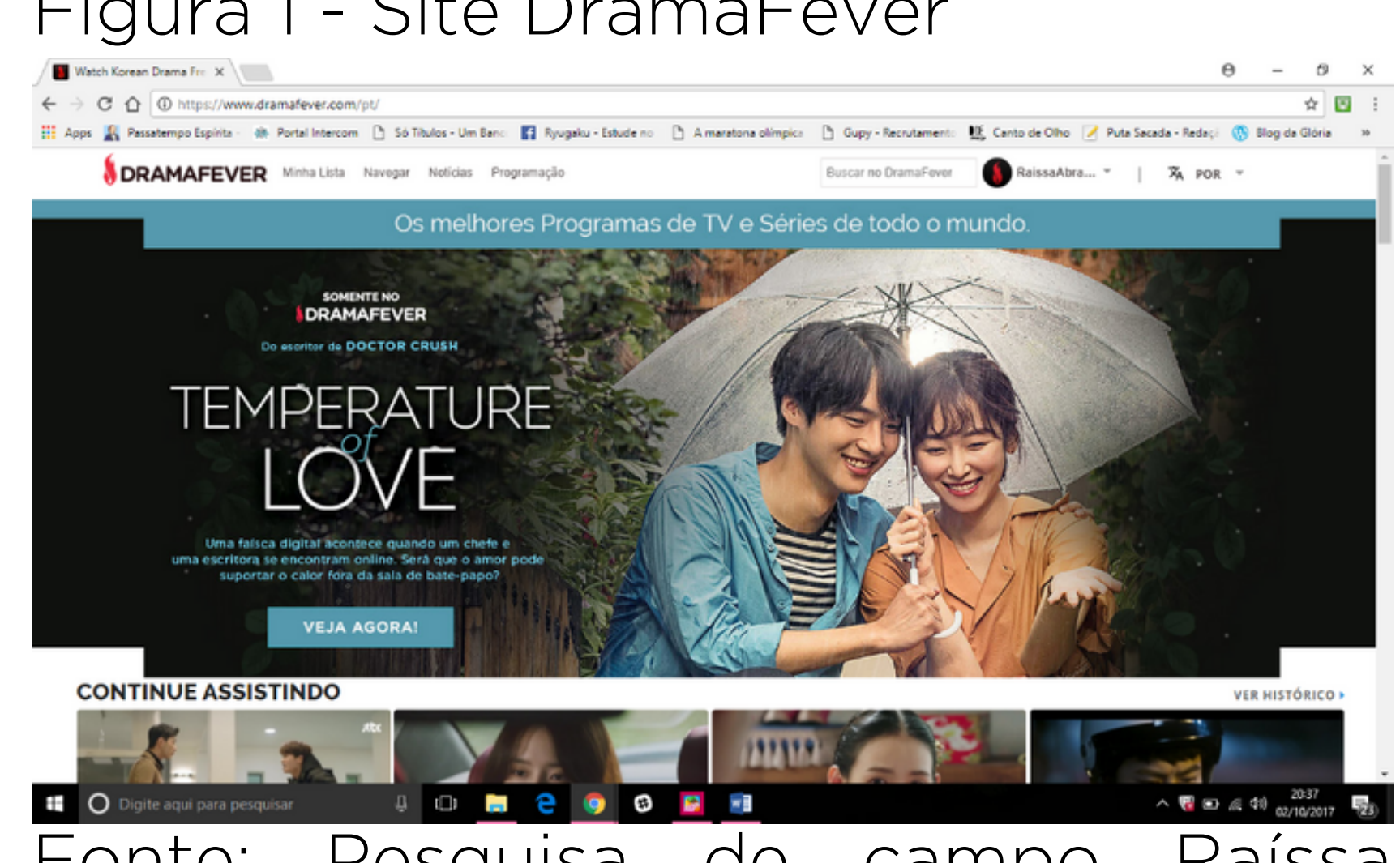

Abraçado, coletado em 10 fev. 2017

\section{CIBERCULTURA E MARKETING}

Uma vez que a revolução digital acabou trazendo mudanças na sociedade, modificou a forma de produzir entretenimento das empresas, de consumir do público, e as esferas da sociedade, ou seja, modificou a cultura.

Surgindo o paradigma da convergência, que "presume que novas e antigas mídias irão interagir de formas cada vez mais complexas" (JENKINS, 2009, p. 37), Jenkins alega que a convergência é a melhor forma de entender as transformações dos meios de comunicação, uma vez que os velhos meios de comunicação não estão sendo substituídos, mas, propriamente, suas funções e status estão sendo transformados pela introdução de novas tecnologias.

Lemos (2002) argumenta que, com o meio digital, a distribuição e o armazenamento são independentes, multimodais, onde a escolha em obter informações sob a forma textual imagética ou sonora é independente do modo pelo qual ela é transmitida. Logo, os consumidores se tornam mais ativos, passando a ter um controle maior dos meios, podendo manipular cada uma das formas midiáticas. Deste modo, os indivíduos assumem posturas não de apenas leitores, no sentido restrito, mas se tornam atores, exploradores e navegadores (LEMOS, 2002). Esses consumidores não se detêm apenas em uma rede ou meio de comunicação, passam a transitar por vários outros, gerando mais conectividade social, o que dá forças para reivindicarem seus direitos de participação na cultura midiática (JENKINS, 2009).

Esses conceitos refletem nos estudos de Jenkins (2009) voltados para o marketing, em que, com a convergência, novas estratégias de marketing surgem para mensurar o envolvimento dos espectadores. Uma dos mais utilizados é a Economia Afetiva, esta "referese a uma nova configuração da teoria de marketing que procura entender os fundamentos emocionais da tomada de decisão do consumidor como uma força motriz por trás das decisões de audiência e de compra" (JENKINS, 2009, p 96). Ou seja, buscam moldar o desejo dos consumidores para que possam ser influenciados nas decisões de compra.

Nos momentos em que a economia afetiva está em vigor, pode-se dizer que os fãs passam a ter mais controle sobre o que é veiculado, pois tendem a assistir e procurar apenas o que está de acordo com os seus interesses. Os anunciantes, agora, são forçados a esperar um convite do consumidor para poder vender algum produto, isso os obriga a entender melhor o seu público e saber o que realmente eles querem consumir para, assim, tentarem entrar nas mentes dos clientes.

Afinal, os consumidores mais valiosos são aqueles fiéis à marca, pois estes tendem a assistir séries com mais fidelidade, prestam mais atenção nos anúncios e compram mais produtos, tornando mais fácil delimitar um padrão e entender os desejos do consumidor. Outro conceito que segue a lógica da convergência é a expressão, também usada para mensurar não apenas a audiência, mas para verificar "o investimento na marca, e não simplesmente uma exposição a ela" (JENKINS, 2009, p. 103). 
A expressão mapeia a atenção

se torna protagonista, porque e programação e à publicidade, o tempo gasto com o programa, o grau de fidelidade do espectador e sua afinidade com 0 programa e seus patrocinadores. [...] Os consumidores não apenas assistem aos meios de comunicação; eles também compartilham entre si ao que assistem - seja usando uma camiseta proclamando sua paixão por determinado produto, postando mensagens numa lista de discussão,

recomendando um produto a um amigo ou criando uma parodia de um comercial que circula na internet. (JENKINS, 2009, p. 103).

Deve-se atentar ao fato de que agora cada consumidor é também um veículo de informação. Dependendo da sua influência na rede de relacionamentos, ele tem o poder de viralizar opiniões, produtos e gostos, seja em maior ou menor escala (LONGO, 2014). Com essa mudança de comportamento, o sucesso das marcas é fundado pelos múltiplos contatos entre marca e consumidor, de modo que as mensagens possam impactá-los emocionalmente, seduzindo-os para um mundo mítico, de forma que possa entreter com mensagens, proporcionando diversão ao consumidor e permanecendo por muito mais tempo na mente deles.

Na era pós-digital, o conteúdo a partir da história contada que - consumidor fará sua escolha. Conteúdos desinteressantes passam despercebidos aos olhos, enquanto aquele que é útil e divertido faz com que as pessoas o procurem na internet e disseminem em suas redes sociais.Longo (2014) chama de IPC (Índice de Potencial de Conteúdo) para a capacidade da marca ou produtor de criar histórias e propostas relevantes e atraentes, tendo três características básicas norteadores para criação de um conteúdo interessante: a Expertise que se refere à autoridade da empresa, sobre determinado assunto, ou seja, o quanto de conhecimento ela possui para discorrer o tema; a Exposição, que é o quanto aquele tema já foi trabalhado na mídia e a Expectativa, que é o quanto $\mathrm{O}$ público está interessado em saber sobre o assunto. Além disso, deve estar aliado à tensionalidade, a qual o ator afirma ser uma capacidade da marca de surpreender os seus consumidores, trabalhando sempre numa tensão com o inesperado. Dessa forma, consegue quebrar a previsibilidade e mantem o público interessado, engajado e apaixonado pela marca (LONGO, 2014).

Vem daí a importância do storytelling na mensagem da empresa, pois é o que a tornará relevante para captar o interesse do consumidor (LONGO, 2014), criando um universo em que as pessoas fazem parte e se interessam em aprender sobre ele, onde buscam ativamente novas informações, novos produtos e, fundamentalmente, envolver-se com outras pessoas durante esse processo. Na era pós-digital está intrínseco o compartilhamento, a colaboração e a generatividade. As pessoas postam suas impressões e experiências positivas ou não compartilhando com a sua rede de conhecidos, possibilitando aos outros acrescentarem comentários, numa ação colaborativa, que gera diversas visões sobre determinada marca ou serviço (LONGO, 2014).

Em uma rede social, uma vez engajados com um conteúdo, é possível observar o que agrada ou não o público, permitindo produzir conteúdo cada vez mais interessante. O ideal é oferecer temas que atribuam valores à vida dos indivíduos, seja algo divertido, único ou emocionante. Deve despertar o interesse das pessoas, sem esperar algo em troca (LONGO, 2014). É necessário fazer com que os fãs se sintam parte da narrativa, cortejando-os, buscando formas de impulsionar o interesse e dando material a eles para que possam propagar o conteúdo de forma espontânea e, assim, tornandoos seus defensores.

É preciso que as empresas encontrem formas de cruzar seus conteúdos com o que já está sendo compartilhado em meio às conversas, atuando como alimento. Estar atento ao timing dos assuntos que circulam na internet é fundamental para que as estratégias de marketing alcancem um desempenho melhor. No mundo pós-digital, a sincronicidade está diretamente ligada à eficiência. As pessoas deixam rastros de si nas redes, comentam seus gostos e preferências, basta saber identificar e adequar ao discurso publicitário (LONGO, 2014).

No entanto, Kotler (2017) afirma que de nada adianta um conteúdo de alta qualidade se 
não atingir o público pretendido. Nesse constante fluxo de informações, é fácil um determinado conteúdo se perder na transmissão. Por isso, os profissionais de marketing precisam assegurar, por meio de uma distribuição adequada e embasada na metodologia dos 8Ps do Marketing Digital Pesquisa, Planejamento, Produção, Publicação, Promoção, Propagação, Personificação e Precisão (VAZ, 2011 apud CRUZ; SILVA, 2014) para que o conteúdo seja descoberto pelo público.

Munido disso, utiliza-se uma nova abordagem, as três categorias básicas de mídia: a Paga, Própria e Ganha. Os próprios nomes das categorias já as identificam, uma mídia paga é aquela onde a empresa paga para ter sua mensagem veiculada, ou seja, os patrocinados que constantemente aparecem na timeline com a intenção de direcionar a atenção dos consumidores para os canais de comunicação da empresa. A mídia própria, são esses canais de comunicação, sites, perfis nas redes sociais (exemplo, Facebook e Instagram) ou tudo aquilo que é de propriedade da empresa, a qual pode servir de mídia, sendo considerados inclusive caminhões de transporte e uniformes. A mídia ganha é a que inclui qualquer manifestação de terceiros a respeito da marca, sejam elas positivas ou negativas, uma vez que, na era digital, qualquer consumidor pode ser um canal de veiculação constante (LONGO, 2014).

\section{INTERAÇÃO MÚTUA E REATIVA}

Na cibercultura, há sujeitos que são atores com capacidade de moldar os meios de comunicação e as trocas simbólicas de conteúdo e compartilhamento se tornam a essência das comunidades no ciberespaço.

Em seus estudos Alex Primo (2000) considera dois tipos de sistemas de interação, a mútua e a reativa, as quais podem existir simultaneamente no ciberespaço. Para rapidamente diferenciá-las, neste artigo trouxe as dimensões que mais são relevantes e necessárias para a análise do objeto.

A interação mútua possui um processo que se identifica pela negociação, ou seja, existem dois ou mais agentes que estão em constante evolução, engajados, e, desse processo de negociação não se pode prever - resultado enquanto na interação reativa é identificada por um processo de estímuloresposta, obtendo o mesmo resultado para o mesmo estímulo. $\mathrm{Na}$ dimensão de Relação, a interação mútua se vale da construção negociada, constantemente construída pelos interagentes, enquanto na interação reativa, é baseada na ação e reação (causal).

O virtual, aqui trabalhado, é um complexo problemático, em que cada agente é livre para modificar o curso das informações, enquanto o potencial é um conjunto de possíveis que aguardam por sua realização e apenas um agente tem liberdade, enquanto o reagente tem apenas a "escolha" de selecionar entre as potencialidades. (PRIMO, 2000). Uma interface plenamente interativa, trabalha na virtualidade, possibilitando $a_{1}$ ocorrência da problemática e viabilizando atualizações e, em uma interface reativa, resume-se ao possível, que espera o clique do usuário para realizar- se.

Para Primo (2000), uma relação homem/máquina está no campo das interações reativas, mas se considerarmos

relacionamento de pessoas com pessoas por meio do computador, então são interações mútuas, Logo, para se identificar quais interações estão presentes é preciso considerar o contexto no qual o seu objeto está inserido.

Tendo em vista o objeto de análise, a fanpage DramaFever Brasil, encontra-se os dois tipos de interações citadas por Primo. Apesar de haver a presença de comentários nas publicações (interações mútuas), as interações reativas são predominantes, as quais podem ser identificadas por meio de cliques em botões de likes, reações e compartilhamentos.

\section{METODOLOGIA}

Selecionou-se um período de três meses, de 01 de fevereiro à 30 de abril de 2018 para fazer a observação e coleta de dados. Foi preferido esse período por ser um momento de lançamentos de vários doramas no início do ano.

A fim de ter uma compreensão mais ampla das interações dos atores, fanpage Dramafever Brasil e usuários, escolhi a netnografia como método, pois, segundo Gebera (2008, apud FRAGOSO; RECUERO; AMARAL, 2011):

A etnografia encarna a percepcão mais convincente para a indagação e a compreensão de interações e interrelações sociais geradas na internet, como resposta à pluralidade de 


$\begin{array}{lll}\text { paradigmas e à estudo em } & \begin{array}{l}\text { profundidade } \\ \text { complexidade das }\end{array} & \text { (PATTON, } \\ \text { matrizes etnográficas } & \text { FRAGOSO; } & \text { RECUER } \\ \text { que se apresentam } & \text { AMARAL, 2011). } \\ \text { nas vivências da rede. } & \\ \text { (GENERA, 2008, p. 2 } & \text { ANÁLISE DAS ESTRATÉGIAS } \\ \text { apUd FRAGOSO; } & \text { DE MARKETING DIGITAL DA } \\ \text { RECUERO; AMARAL, } & \text { FANPAGE DRAMAFEVER } \\ \text { 2011, p. 171). } & \text { BRASIL }\end{array}$

A netnografia se faz útil ao explorar as relações existentes no campo virtual, uma vez que viabiliza observar detalhadamente as formas de interação no ciberespaço, sendo uma metodologia ideal para estudar perfis de consumo dos indivíduos em rede, devido aos rastros comunicacionais nos sites de redes sociais (AMARAL; NATAL; VIANA, 2008). Portanto, possibilitando identificar os hábitos de consumo e as formas de interação do grupo consumidor na esfera do ciberespaço, uma vez que os dramas coreanos são compartilhados

disponibilizados na internet, acredita-se que é no meio digital que o público em questão se encontra.

Para auxiliar no método netnográfico, optou-se pelas pesquisas qualitativas, pois, essas tendem a uma compreensão aprofundada e holística dos fenômenos em estudo e, para tanto, contextualiza e reconhece o caráter dinâmico da internet (FRAGOSO; RECUERO; AMARAL, 2011). As amostras qualitativas buscam por elementos mais significativos para o problema do que elementos probabilísticos como é o caso de amostras quantitativas, sendo elas tipicamente intencionais. Com foco no problema desta pesquisa, as amostras qualitativas irão servir para selecionar casos informacionalmente ricos para o

\section{Interação entre marca e consumidor}

Em vista de analisar as estratégias de marketing digital, observou-se nesses três meses de coleta de dados, uma certa unidade nos conteúdos veiculados na fanpage DramaFever Brasil, tais como, cenas de dramas, trailer, memes, divulgação dos novos dramas, o canal Club do Dramafever e notícias relacionadas ao entretenimento do universo asiático, sobre os atores, cantores e outros, as quais, de alguma forma, tentam direcionar para o plataforma de streaming.

Nota-se que todo conteúdo produzido está de acordo com o seu universo e segue O IPC citado por Longo (2014) como norteadores para um conteúdo de qualidade, em que é trabalhada a expertise, uma vez que a sua autoridade é em doramas asiáticos, trazendo informações relacionadas a esse universo. Percebe-se que poucas ou inexistentes são as páginas brasileiras no Facebook que tratem de dramas asiáticos com o caráter comercial que o DramaFever possui. $O$ seu concorrente direto, site Viki, não possui uma versão de fanpage brasileira, sendo assim, os outros produtores desse conteúdo no Brasil são fóruns, (grupos) que possuem uma dinâmica diferente de uma fanpage. Apesar de ter seus pontos positivos no conteúdo,
- Dramafever Brasil exercita muito pouco sua tensionalidade: não é identificado uma quebra na previsibilidade, portanto, já é esperado o tipo de conteúdo que será disponibilizado a cada dia na página.

A marca consegue criar e manter seus consumidores engajados por meio do storytelling, esse método se torna mais favorável porque trabalha com produtos de narrativas, assim, utilizam-se enredos dos dramas para envolver o público, despertar emoções, muitas vezes trazendo-os para dentro da narrativa e incentivando um mundo de sonhos em que a maioria dos consumidores adorariam viver.

Portanto, de acordo com os estudos de Jenkins (2009) em que ele afirma ser um ótimo recurso as emoções, pois é ilimitada e sempre está disposta a associar-se a novas ideias, é possivel afirmar que 0 DramaFever Brasil trabalha com excelência esse recurso, proporcionando entretenimento à vida de seus consumidores e convertendo em fidelidade, percebidas nas postagens compartilhadas e comentários. De acordo com as teorias de cibercultura abordadas nesta pesquisa, os consumidores buscam e compartilham informações das quais são de seu interesse, expressando suas opiniões, sejam elas positivas ou não, em sua rede.

A fanpage está constantemente atenta aos assuntos discutidos pelo grupo no momento, apesar de que tem um certo controle sobre as demandas, visto que utiliza muitos lançamentos de dramas como assunto. Geralmente são de 3 a 4 lançamentos no período, assim 
mantendo a sincronia com o público que está acompanhando - o qual Longo (2014) diz ser essencial para o desempenho das ações - e acaba estimulando o interesse dos que ainda não acompanham.

É notável a alta frequência de dramas coreanos na timeline - mesmo havendo o lançamento de dramas de outras nacionalidades - $\quad$ esses geralmente são os preferidos pelo público, logo, pode-se afirmar que página produz o conteúdo de acordo com os gostos de seus seguidores, que podem ser identificados pelo engajamento nas publicações. Sendo assim, observa-se a via de mão dupla estabelecida pelo diálogo entre consumidor e marca.

\section{PUBLICAÇÕES}

Dentre as publicações coletadas, selecionou-se para esse recorte as três mais relevantes à pesquisa. A primeira publicação (figura 2) é mais engajada dos três meses de coleta, com 1.675 de engajamento. $\bigcirc$ vídeo possui uma cena de Oh My Venus, drama lançado em 2015 e que aparentemente está enquadrado na lista dos favoritos, devido ao nível de engajamento.

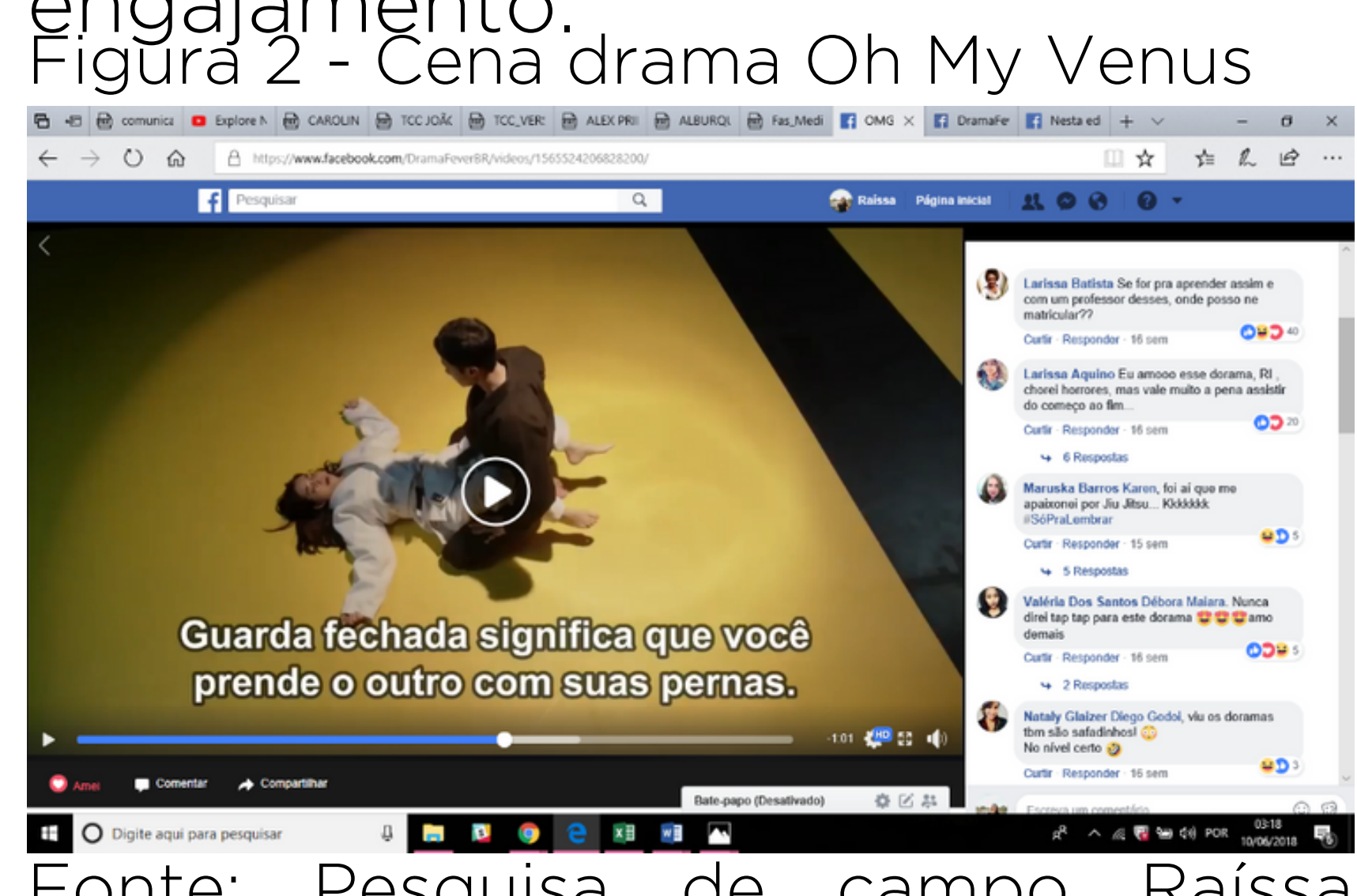

Fonte: Pesquisa de campo Raíssa Abraçado, coletado em 10 jun. 2018

A publicação ganhou comentários bastante parecidos, que envolvem o ator, recomendação do drama para amigos, pessoas com curiosidades sobre ele, outras com saudades, afirmando ser um excelente dorama. Infere-se que a cena despertou um sentimento de nostalgia no público, uma vez que relembra um dos episódios favoritos. Nota-se que, devido ao engajamento na publicação, a marca ganha uma mídia gratuita positiva, estabelecendo uma interação reativa por meio das reações acionadas.

A segunda publicação (figura 3) aborda um drama clássico, Boys Over Flowers (BOF) lançado no ano de 2009, com engajamento de 843. Esse drama normalmente possui bastante repercussão devido a sua popularidade. A estória obteve tanto sucesso que, até os dias de hoje, continua sendo um dos dramas mais assistidos. Pode-se confirmar que, devido à repercussão, houve uma grande expressão na postagem. Jenkins (2009) caracteriza essa expressão como um investimento na marca, ou seja, foi compartilhada e gerou discussão.

Figura 3 - Drama Boys Over Flowers

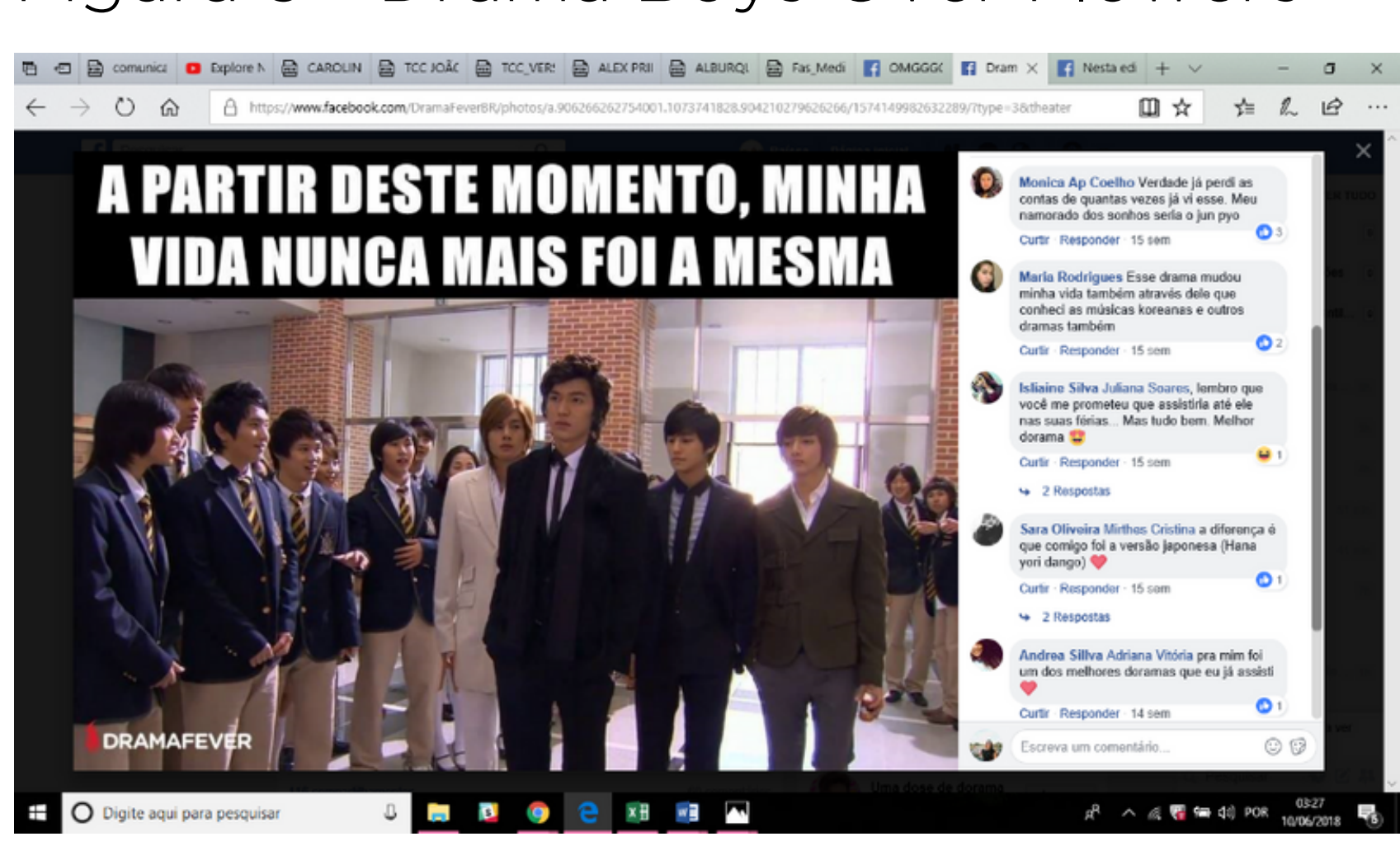

Fonte: Pesquisa de campo Raíssa Abraçado, coletado em 10 jun. 2018

Observa-se, também, o caráter afetivo na postagem, reafirmando um sentimento comum entre os consumidores, afinal, para muitos, o BOF foi o primeiro drama assistido. Por isso, ao utilizar o texto na publicação "A partir deste momento, minha vida nunca mais foi a mesma", gera conexões instantâneas com outros niveis de experiências, que levam o consumidor a outro patamar de sensações, fazendoo entrar em contato com suas impressões, gerando um sentimento de pertencimento com esse grupo.

A terceira publicação (figura 4) é uma brincadeira que fizeram com os usuários, "Comente o nome do seu dorama favorito e espere alguém dar uma nota de O a 10", o post teve 657 de engajamento.

Figura 4 - Postagem com montagem

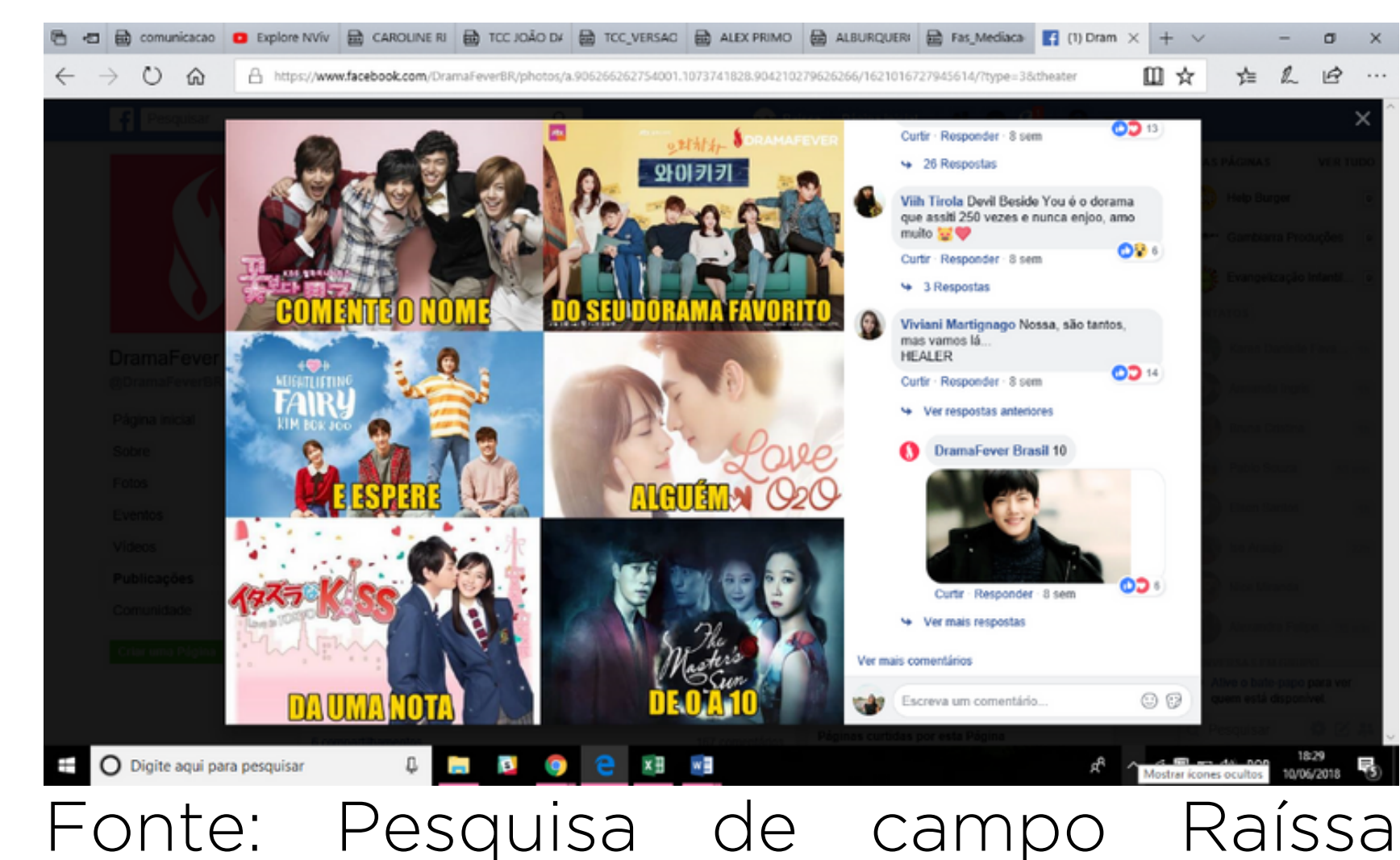

Abraçado, coletado em 10 jun. 2018

Nota-se 0 expressivo envolvimento com o conteúdo, uma vez que convida aos usuários a comentarem sobre seus gostos e desperta a curiosidade de saber se outras pessoas teriam o mesmo sentimento pelo drama favorito. É interessante ressaltar que esse é um dos poucos posts observados que a página interagiu mutuamente nos comentários, comentando a sua própria nota.

Outra consideração é a escolha das imagens dos dramas, é gossível que sejauma forma de dramas que estão disponíveis na plataforma, disponibilizando simbolicamente o seu material e estimulando o consumidor a expressar sua opinião (JENKINS 2014), produzindo seu próprio conteúdo na páginas com os comentários que essa mídia 
ganha, ou seja, quaisquer manifestações de terceiros sobre a marca e acabam estimulando outras pessoas a ir buscar os produtos citados (KOTLER, 2017).

\section{CONSIDERACCÕES}

Durante a análise na fanpage Dramafever Brasil, encontrou-se padrões de conteúdos que ajudaram a entender os hábitos de consumo desse público e a relação da marca com os consumidores. Assim, foi possivel identificar as estratégias de marketing digital utilizadas para divulgar os produtos, criar laços e sentimento de pertencimento. Compreendeu-se que o DramaFever tem o cuidado em manter suas relações, estimulando $O$ interesse na marca e reafirmando os valores identificados no grupo.

Apesar de não ser observada uma interação mútua entre a página e o consumidor, ou seja, uma relação construída pelo diálogo (PRIMO, 2000), nota-se apenas a interação reativa, identificada nas reações do Facebook. Observa-se apenas interação mútua entre os usuários que utilizam de comentários para expressar os seus sentimentos, seja com amigos de suas próprias redes (por meio das marcações), seja respondendo ao comentário de outras pessoas.
REFERENNCIAS

AMARAL, Adriana; NATAL Geórgia; VIANA, Luciana. Netnografia como aporte metodológico da pesquisa em comunicação digital. Cadernos da Escola de Comunicação, v. 6, 2008, p. 1-12. Disponivel em <http://portaldeperiodicos.unibr asil.com.br/index.php/cadernosc omunicacao/article/viewFile/195 8/1535>. Acesso em 12 jun. 2018.

FRAGOSO, SUely; RECUERO, Raquel; AMARAL, Adriana. Métodos de pesquisa para internet. Porto Alegre: Sulina, 2011.

JENKINS, Henry. Cultura da Conexão: criando valor e significado por meio da mídia propagável. São Paulo: Aleph, 2014.

\section{Cultura da}

Convergência. 2.ed. São Paulo: Aleph, 2009

\section{KOREAN CULTURE AND}

INFORMATION SERVICE. The

Korean Wave: A New Pop

Culture Phenomenon. 2011 a.

Disponivel em:

<http://www.kocis.go.kr/eng/op enPublications.do>. Acesso em: 30 jun. 2019

\section{K-Drama: A New TV}

Genre with Global Appeal. 2011b. Disponivel em:

<https://issuu.com/kocis9/docs /2011_k-drama_en_0119>. Acesso em: 12 jun. 2019

KOTLER, Philip. Marketing 4.0. Hermawan Kartajaya, Iwan Setiawan. Rio de Janeiro: Sextante, 2017

\section{LEMOS, André. Cibercultura:}

tecnologia e vida

social na cultura

contemporânea. ed. 7. Porto

Alegre: Sulina, 2002
LONGO, Walter. Marketing e Comunicação na era pós-digital: as regras mudaram. São Paulo: HSM, 2014.

MADUREIRA, Alessandra; MONTEIRO, Daniela; CORTEZ, Krystal. Fãs, mediação e cultura midiática: dramas asiáticos no Brasil. In: I Jornada Internacional GEMIn/S, 13,14 e15 de maio de 2014. Disponivel em:

<http://docplayer.com.br/2950 8403-Fas-mediacao-e-culturamidiatica-dramasasiaticos-nobrasil-1.htm/>. Acesso em: 12 jun. 2019.

PRIMO, Alex. Interação Mútua e Interação reativa: uma proposta de estudo. Revista FAMECOS, n.12, jun. 2000.

REZ, Rafael. O que é storytelling? Nova Escola de Marketing. 09 fev. 2017.

Disponivel em:

<https://novaescolademarketing com.br/marketing/o-que-e storytelling/>. Acesso em: 12 jun. 2018

SPANGLER, Todd. Warner Bros. DramaFever Korean-Drama Streaming Service Is Shutting Down. Variety, 16 out. 2018. Disponivel em.

<https://variety.com/2018/digi al/news/dramafever-k-dramashutting-down-warner-bros1202982001/>. Acesso em: 22 ago. 2019

\footnotetext{
1 - Drama Taiwanês.

2 - Drama Coreano

3- Drama Chinês.

4 - Palavra japonesa para Drama.

5 - Storytelling é a capacidade de contar histórias de maneira relevante. É um método que promove o negócio sem que haja a necessidade de fazer uma venda direta. Em outras palavras, o storytelling tem um caráter muito mais persuasivo do que invasivo (REZ, 2017).

6 - Em tradução livre: "ao tempo".
} 
Recebido em 23 ago 2019 | Aprovado em 05 dez 2019

Raíssa Abraçado

Graduada em Comunicação Social - Publicidade e Propaganda pela Universidade da Amazônia

(UNAMA)

E-mail: raissa_abracado@hotmail.com

Danuta Leão

Doutoranda do Programa de Pós-graduação Comunicação, Linguagens e Cultura (PPGCLC) da Universidade da Amazônia (UNAMA). Professora da Universidade da Amazônia (UNAMA) e da Faculdade de Estudos Avançados do Pará (FEAPA). Membro do Grupo de Pesquisa Consumo, Identidade e Amazônia-CONSIA.

E-mail: danutaleaopp@gmail.com 